\title{
The Mixed Teaching Mode of College English in the Practice Community
}

\author{
Shuyi Teng \\ Heilongjiang Technology College, Jixi
}

Keywords: college English; mixed teaching model; practice community

\begin{abstract}
In the course of college English reform, the mixed teaching mode belongs to the direction of reform focus. It effectively integrates online learning and classroom teaching modes, which can improve the quality of college English teaching. This paper analyzes the three core components of online learning, in-class application, and extracurricular practice in the college English mixed teaching model. Based on the combination of the teaching theory and teaching practice, this paper designs the practice community architecture of college English and analyzes the advantages of implementation college English comprehensive teaching model. A study found that college English practice community can help college students to make further their understanding of English knowledge in language practice, and build up a perfect English knowledge system to effectively cultivate college students' practical ability in English.
\end{abstract}

\section{Theory of Practice Community}

The practice community is also called the practical community and the practice society, and it was first put forward by the sociologist Lave et al. The practice community mainly refers to people in a particular field of knowledge who are in contact with each other and share knowledge in this field around this community. The knowledge domain, practice, and community are the main components of the practice community. The knowledge domain determines the interests and identities of each member of the community. They are motivated by common aspirations to apply, share, and innovate together to help each other achieve common growth. The community belongs to the social context of learning, members can help each other, learn together and practice together; practice requires members to actively participate in the learning process, and the practical application of shared knowledge, apply it to practice, gain new knowledge through innovation. The practice community can help students to learn effectively, and they can continuously feedback during the process of knowledge transfer, forming the community as a learning subject and generating more dynamic knowledge while satisfying individual learning needs. The participation and management of the organization can promote the development of the practice community and enhance the sharing effect of knowledge. The application of this theory to college English teaching can improve the classroom construction structure and enhance the teaching effect.

Composite Teaching Model of College English

The composite teaching effectively combines face-to-face and online teaching methods and effectively blends modern information technology, belonging to the necessary result of teaching reform. It can be concluded on study that the composite teaching effectively can be divided into three parts: online study, in-class application and extracurricular practice, which are mutually connected and melted together, as well as they creating rich context and language application environment for college English teaching. Compared the traditional English classroom teaching model, the composite teaching model can effectively promote students' self-learning to make sure students to study by themselves and cooperation study. Based on the combination of mixed teaching theory and applied teaching practice, a hybrid teaching model was constructed based on the teaching characteristics of college English.

For one thing, in the process of the composite teaching of college English, online study mainly makes use of small-large private online courses and adopts the teaching resources of language knowledge study and online study community. During the study, students can watch teaching designing micro-class video of college English to systematically study language knowledge and lie 
in class content to take relevant exercises and tests online to continuously strengthen their own English knowledge and to promote English standard. Online study community belongs the exercise for all the students to mutually communicate in the form of publish posts and reply to others to communicate with teachers and other students, where they can discuss the puzzles in class and share more English knowledge and experience by communication. Secondly, the in-class application mainly refers to face-to-face communication with teachers after students learning about the curricular content on the online study platform and systematically gets English knowledge. The composite English teaching is quite different from the traditional teaching model, which is not only to teach students English knowledge but also sets study themes, creates English application context, makes use of different English skills to make sure students participate in problem discussion, language games, knowledge presentation, team report and so on as well as continuously improving English ability by team cooperation. In the end, it is extracurricular practice that is the key component part of the composite teaching model. After online study and curricular language application, colleges would put the English knowledge that students have studied into practice by holding practical activities. The extracurricular practice mainly goes around the set themes to carry out actual language practice, which is a kind of extension for classroom study. For instance, students can be requested to design posts in cooperation way, to do surveys, to make videos and other tasks together with presenting students online in English language and cultivating their own English application ability.

During using the composite teaching model of college English, students are the active composer of knowledge who mainly acquires English knowledge by team cooperation and online study. The study method is greatly changed and the way sets a higher requirement for students' self-study ability, cooperation ability and English timing ability. To improve English teaching effect, it is necessary for teachers to create a practice community so as to provide more knowledge for interactive English study and common practice. Thus, students' study interest can be effectively inspired and they would actively participate in the process of the composite teaching.

\section{Advantages of Mixed Teaching Model}

First of all, as far as the teachers, they can effectively use animations, sounds, and other tools to enhance the interest of the English classroom and provide more English learning information and enrich the content of classroom teaching. In this way, teachers do not need to bring a lot of paper-based extracurricular materials for class, which enhances the convenience of teaching. In the meanwhile, it is also possible to change the teacher's teaching mode, from the previous simple classroom teaching to multimedia teaching, which enhances the vividness of the classroom and improves the teacher's teaching quality. As a result, the composite teaching is a new type of learning concept. Students belong to the main body of study while teachers play a leading role. This kind of teaching model reaffirms the role of teachers in teaching. Secondly, as far as students, the composite teaching provides more opportunities for university students to participate in English classroom learning than traditional English teaching methods. This allows for two-way interaction with teachers and improves teaching efficiency. At the same time, the composite teaching model also provides students with more learning resources and enhances their learning initiative. Under the composite teaching model, students can not only exert their own learning characteristics, but also can study independently, attach importance to individual differences among students, and achieve targeted teaching. Apart from, as far as teaching effect, the composite teaching model adopts modern information technology such as multimedia, which not only enriches the content of classroom teaching and improves teaching efficiency but also provides more exhibition space for modern English learning. In the end, as far as management, in the mode of the composite teaching, the getting speed of network resources directly affects the teaching effect and the management should supervise the situation of students' self-study. In addition, the composite teaching mode puts forward higher requirements for time management, technology management and so on, which can provide more management experience for managers and improve their network management ability. 


\section{Structure of Practice Community in College English Mixed Teaching Model}

The practice community in the mode of college English composite teaching is the study organization composed of teachers and students. Students can cooperation with each other, practice together in the discussion and negotiation with other students and teachers to continuously build up the abilities of acquiring English knowledge and practical application. Based on combining the college English composite teaching practice and the theory of community, the articles analyzes the basic structure of the practice community in the mode of college English composite teaching, including members, study activities and study objectives three parts in all.

\subsection{Members}

The 1,603 students who attended the college English composite teaching as students in Grade 2015 of University of Science \& Technology Beijing, are different majors and study English knowledge, communicate, complete English application and English time tasks with other members in the curriculum system of SPOC on the study platform MOOC. The members of the college English practice community generally include three types of roles: the first is the initiator, mainly referring to teachers and teaching assistants. The teacher mainly publishes teaching resources online through the learning platform and organizes the release of classroom communication stickers, offline discussion and layout. Collaborative projects and other activities promote the formation of a community of practice. The assistant teacher is responsible for answering student's doubts online and ensuring the normal operation of the community. The second is the core members, that is, the key personnel with strong English ability and excellent academic performance. They will answer questions online and lead practical activities to share their learning experiences for students and lead other members to study together. The third is general members, who are English study participants. They mainly complete the online and offline study tasks according to the English study requirements, and conduct knowledge exchange under the leadership of the sponsors and core members to complete practical study. Unlike the study group in the traditional teaching model, the members of the practice community of the composite teaching model have common study objectives and are ready to study in practice and continue to develop rich and shared resources.

\subsection{Study activities}

The practice community in the composite teaching model has the same study prospect. In the short term, it needs to complete the English study tasks in the university stage and improve English performance. In the long term, it needs to improve the practical application ability of English through curriculum learning. Driven by a common prospect, members of the practice community need to actively participate in various study activities. The first is the self-directed online study course where students acquire the required English knowledge in the micro class video and complete online exercises. Community members can discuss classroom problems with other members at any time in the discussion forum. All members work together to solve their own study experiences. Followed by face-to-face classroom study, teachers need to create appropriate study situations for students and share study results online, so that students in the process of common study continue to consolidate their own knowledge. Lastly, it is to sort out knowledge and improve English application ability. This stage mainly completes the English time project that the teacher arranges with other community members and enlighten each other during the time to promote the application ability of language knowledge.

\subsection{Study objectives}

Practice community members have the same study objectives of improving English practical application ability by online study, classroom teaching, extracurricular practice to attend language application, skill promotion and so on. No matter the interactive student activities online, or the completion of classroom application projects, the students can share knowledge and build up, enrich the knowledge system in the application. The extracurricular practice projects require students to make use of online study and the results of class study to revert the theories into their own 
knowledge and keep innovating new knowledge. With the completion of teaching system, the practice community members will complete their circulation of acquiring English knowledge.

Influence on College English Composite Teaching of Practice Community

With the rapid development of modern information technology, the study approaches of learners have greatly changed. College English classes also use the composite teaching mode that is fully combined with modern technologies and class teaching. As the study body, college students should change their own study methods to adapt the teaching mode. In the past, English teaching mainly adopted the theory teaching approach. To make students adapt the new teaching approach, teachers should create the practice community to provide students with communication meeting, interactive cooperation and the platform of sharing knowledge to ensure the implementation of the college English composite teaching mode.

\subsection{Supporting cooperative study to effectively acquire knowledge}

The students, who participate in the composite teaching mode, belong to the members of the practice community. They have the same study objectives and knowledge field and they are all English learners, sharers and creators. In the course of studying English knowledge, the sponsors and key members of the practice community and ordinary members will have an influence on each other and accumulate more study experience in the process of discussion, as well as completing English practice projects in the course of mutual coordination to improve English application ability.

\subsection{Promote language application, and perfect knowledge structure}

In the theory of the practice community, English knowledge study comes out the process of building up knowledge and coordination. The college English practice community stresses the joint study process of members but not simple knowledge input. In the whole practice community, all members and teachers take part in the process of English application and share their own experience to build up the new knowledge system in practice by online study, curriculum application and extracurricular practice.

Support Language practice, Transform Knowledge System. The practice community should take practice as the main study activity and all the members actively take part in online, in-class and extracurricular activities and change explicit and implicit knowledge. During the period, students can keep improving their English practice ability and transform the implicit knowledge into the explicit knowledge. Thus, their experience would be strengthened in practice to ensure them to be the genuine body of English study activity.

\section{Conclusion}

Under the background of information teaching, the composite teaching mode is the necessary development trend of the college English reform that melts the teaching content of college English and modern advanced education technologies. To strengthen the effect of teaching implementation, college English teachers should change the previous traditional teaching methods and students should change study approaches to acquire more language study and application support. And the practice community of building up college English composite teaching mode can meet the target. In the teaching mode, students can communicate by themselves and share knowledge in the process of studying English and better digest what they have studied in the process of language practice. Thus, the implementation of online teaching and in-class teaching can be improved as well as the ability of students applying English knowledge into practice. Afterwards, the teaching mode of the composite teaching mode practice community with online and offline theory and practice teaching should be further researched by bringing in more modern information technologies and discussing effective English study schemes to promote the reform of college English teaching. 


\section{References}

[1] Yang Chunxia, Zhu Meihong, Li Xiaoyan. Study on College English Composite Teaching Mode in the surroundings of "Internet+" [J]. Guidebook of Science and Education (Last Part of Month), 2017(05).

[2] Jin Peiyu. Application in College English Teaching of "Internet+Composition” Teaching Mode and Assessment Mechanism[J]. Academic Journal of Jilin Engineering Normal University, 2017(07).

[3] Li Ying. Research on College English Composite Teaching Mode[J]. Academic Journal of Bohai University (Philosophical Social Science Version), 2016(11).

[4] Zhang Yi, Gao Jian. Study on Application of College English Composite Teaching Mode-- Take a university sample as example[J]. China Education Information, 2015(09).

[5] Zhao Yu. College English Teachers' Opportunities and Challenges in the Background of MOOCs[J]. Academic Journal of Xianyang Normal University, 2017(03). 